UPPSALA UNIVERSITET
Working Paper 2008:15

Department of Economics

\section{Delegation, Time Inconsistency and Sustainable Equilibrium}

Henrique S. Basso 
Department of Economics

Working paper 2008:15

Uppsala University

October 2008

P.O. Box 513

ISSN $1653-6975$

SE-751 20 Uppsala

Sweden

Fax: $+{ }_{4} 6184711478$

Delegation, Time Inconsistency and Sustainable Equilibrium

Henrique S. BASSO

Papers in the Working Paper Series are published on internet in PDF formats.

Download from http://www.nek.uu.se or from S-WoPEC http://swopec.hhs.se/uunewp/ 


\title{
Delegation, Time Inconsistency and Sustainable Equilibrium*
}

\author{
Henrique S. Basso ${ }^{\dagger}$
}

October 2008

\begin{abstract}
This paper analyzes the effectiveness of delegation in solving the time inconsistency problem of monetary policy using a microfounded general equilibrium model where delegation and reappointment are explicitly included into the government's strategy. The method of Chari and Kehoe (1990) is applied to characterize the entire set of sustainable outcomes. Countering McCallum's (1995) second fallacy, delegation is able to eliminate the time inconsistency problem, with the commitment policy being sustained under discretion for any intertemporal discount rate.
\end{abstract}

JEL Classification: E52, E58, E61

Keywords: Central Bank, Monetary Policy, Institutional Design

\footnotetext{
${ }^{*}$ This paper is drawn from my PhD dissertation at the University of London - Birkbeck College. I would like to thank John Driffill, Emanuela Sciubba and two anonymous referees for helpful comments. Financial support from the Economic and Social Research Council (award PTA-030-2003-01236) is gratefully acknowledged.

${ }^{\dagger}$ Department of Economics, Uppsala University, P.O.Box 513, SE-751 20, Uppsala, Sweden, e-mail: henrique.basso@nek.uu.se
} 


\section{Introduction}

Delegation of monetary policy to an independent central bank is now followed by a large number of governments and is generally considered an important device to mitigate the time inconsistency problem of monetary policy, as identified by Kydland and Prescott (1977) and Barro and Gordon (1983). Nonetheless, the economic theory has not yet achieved a consensus on whether delegation is indeed the answer to that problem. While Rogoff (1985), Walsh (1995) and Svensson (1997), amongst others, come in defence of delegation stating that it is an efficient remedy, McCallum $(1995,1997)$ state that delegation of monetary policy merely relocates the time inconsistency problem from the monetary policy decision to the institutional design and maintenance decision. If the government can not commit to confirm the optimal monetary policy plan, it will have the same problem in committing to enforce the contract set for the central bank. Thus, delegation as a solution to the time inconsistency problem is a fallacy.

While the majority of the literature on delegation follows Barro and Gordon (1983), this paper develops a structural model of monetary policy making to reevaluate the effectiveness of delegation as an instrument to overcome the time inconsistency problem. In order to answer McCallum's criticism the government here not only appoints an independent central bank, but is also allowed to reappoint the central bank after expectations are formed.

Jensen (1997) was the first to formalize McCallum's argument, setting up a model that includes delegation and costly central bank reappointment. He shows that delegation leads to a decrease in the inflation bias, but it can not resolve the time inconsistency problem; it actually worsens it. Recently, Driffill and Rotondi (2006), using the same model, dispute this result showing that if the appointment strategy is modified, delegation can still mitigate the time inconsistency problem, although this is only achieved if the central bank is constantly reappointed. The analysis presented here argues that delegation is in fact able not only to mitigate, but to eliminate the time inconsistency problem, in some cases without the need for constant reappointments.

Both Jensen (1997) and Driffill and Rotondi (2006) base their analysis on the Barro and Gordon's (1983) framework. Despite its elegance, the framework relies on a simple tit-for-tat punishment strategy and ad-hoc central bank/government objective functions. The present work analyzes delegation using a microfounded model where the government maximizes the welfare of the representative household, building on Ireland (1997). Furthermore, it does so using a model in which the equilibrium is a well defined sub-game perfect equilibrium or a sustainable equilibrium (Chari and Kehoe 1990). The framework here explicitly models the choice of delegation, reappointment, monetary policy and allocations as an interaction between two big players, the government and the central bank, who behave strategically and a large number of small players, the agents, comprising of the firms and the representative household, who behave competitively. Therefore, the two main criticisms of Barro and Gordon's (1983) approach are addressed. 
In order to re-assess Jensen's (1997) and Driffill and Rotondi's (2006) results, our initial analysis is done assuming the government's reappointment cost function is quadratic. However, under this functional form the cost of reappointment, at the margin, is zero. As a result, the government always finds it optimal to change the central bank at every period. In reality it is likely that any reappointment, even if the new central bank is very similar to its predecessor, might carry a non-neglectable cost to a first order approximation. In view of that, we modify the government's reappointment cost function, considering an absolute value function as well.

With no reappointment costs, the assertion that delegation only relocates the time inconsistency problem is confirmed. However, when reappointment is costly, contrary to the results in Jensen (1997) and Driffill and Rotondi (2006), either the time inconsistency problem is eliminated or the optimal monetary policy is more credible. ${ }^{1}$ If the reappointment cost function is quadratic, delegation eliminates the time inconsistency problem for all economies independent of the discount factor; the optimal monetary policy is sustained without trigger-type/reputation based strategies, or equivalently the sustainable equilibrium is also a Markov equilibrium. Nonetheless, as in Driffill and Rotondi (2006), the central bank is constantly reappointed.

For an absolute value cost function, the solution depends on the magnitude of the reappointment cost relative to the economy's welfare, highlighting the relevance of this parameter for the results. If the reappointment costs are significant, the commitment solution is sustained under discretion for all economies, without constant reappointments. Otherwise, trigger strategies are needed, but the introduction of delegation makes the commitment solution sustainable in economies where it was not possible to do so in its absence. Therefore, contrary to the arguments presented by McCallum, (1995, 1997), the structural model presented here reinforces the view that delegation can be used to overcome the time inconsistency problem of monetary policy, though no commitment technology on the maintenance of the central bank contract is assumed. Driffill and Rotondi's (2006) conclusions also come in defence of delegation, but the results here are stronger since the time inconsistency problem is eliminated and the central bank is not constantly reappointed.

The remaining of the paper is organized as follows. Section 2 presents the model and section 3 shows its solution under commitment. The main results of the paper, where monetary policy is discretionary, are presented and discussed in section 4. Section 5 concludes. An appendix is used to present additional proves.

\footnotetext{
${ }^{1}$ Credibility is interpreted here as in Jensen (1997); an increase in credibility implies that the set of discount factors for which the optimal commitment monetary policy is a sustainable equilibrium is enlarged.
} 


\section{Model}

The economic environment is similar to that of Ireland (1997) and includes $(i)$ a representative household, (ii) a continuum of monopolistic firms indexed by $i \in[0,1]$ and (iii) a governmental structure which sets monetary policy.

The representative household maximizes its utility derived from consumption and leisure subject to a cash-in-advance constraint and a standard budget constraint. The household problem $(\mathrm{H})$ is given $\mathrm{by}^{2}$

$$
\max _{\left\{\Omega_{t}\right\}_{t=0}^{\infty}} U_{0}=\max _{\left\{\Omega_{t}\right\}_{t=0}^{\infty}} \sum_{t=0}^{\infty} \beta^{t}\left(\frac{\left(c_{t}\right)^{\alpha}}{\alpha}-n_{t}\right)
$$

subject to

$$
\begin{aligned}
c_{t}= & {\left[\int_{0}^{1} c_{t}(i)^{\frac{(\theta-1)}{\theta}} \mathrm{d} i\right]^{\frac{\theta}{(\theta-1)}}, \quad n_{t}=\int_{0}^{1} n_{t}(i) \mathrm{d} i, } \\
& \int_{0}^{1} p_{t}(i) c_{t}(i) \mathrm{d} i+b_{t+1} x_{t} / R_{t}+m_{t+1} x_{t} \\
\leq & m_{t}+\left(x_{t}-1\right)+b_{t}+\int_{0}^{1} d_{t}(i) \mathrm{d} i+w_{t} n_{t}
\end{aligned}
$$

and

$$
\int_{0}^{1} p_{t}(i) c_{t}(i) \mathrm{d} i \leq m_{t}+\left(x_{t}-1\right)+b_{t}-b_{t+1} x_{t} / R_{t} .
$$

Where $c_{t}$ is a consumption index, $c_{t}(i)$ is the consumption of good $i, n_{t}$ is the number of hours worked, $m_{t+1}$ is the cash holdings and $b_{t+1}$ is the bond holdings. $\Omega_{t}$, the household allocation at time $t$, is given by the set $\left\{c_{t}, c_{t}(i), n_{t}, m_{t+1}, b_{t+1}\right\}$. The household behavior is, therefore, summarized as the set of allocations $\Omega=\left\{\Omega_{t} \mid t=0,1, \ldots\right\}$.

$R_{t}$ is the bond interest rate, $w_{t}$ the wage, $p_{t}(i)$ is the price of good $i$ and $d_{t}(i)$ the profits of firm $i$ (defined below). $x_{t}$ is the money growth rate determined by the governmental structure. As in Ireland (1997), $x_{t}$ is bounded, $x_{t} \in[\beta, \bar{x}]$, to ensure a monetary equilibrium. The lower bound ensures that nominal interest rate is non-negative and the higher bound ensures that the household never abandons the use of money.

Two other important parameter restrictions are imposed: $0<\alpha<1$, to ensure concavity of the utility function and a well defined utility at $c_{t}=0$, and the elasticity of substitution, $\theta$, is greater than one, to ensure the existence of equilibria with monopolistic competitive firms.

\footnotetext{
${ }^{2}$ Following Ireland (1997), all lower case variables are nominal variables divided by the money supply $M_{t}^{S}$.
} 
It will also be helpful in our analysis to consider the household problem in its recursive form $(\mathrm{H}-\mathrm{R})$. That is

$$
v_{H}\left(m_{t}, x_{t}\right)=\max _{\Omega_{t}}\left[\frac{\left(c_{t}\right)^{\alpha}}{\alpha}-n_{t}+\beta v_{H}\left(m_{t+1}, x_{t+1}\right)\right]
$$

subject to the same constraints.

Firm $i$ production function is $y(i)=n(i)$. At time $t=0,1, \ldots$ each firm sets $p_{t}(i)$ to maximize profits (problem $(\Lambda)$ )

$$
d_{t}(i)=\left(p_{t}(i)-w_{t}\right)\left(\frac{p_{t}(i)}{p_{t}}\right)^{-\theta}\left(\frac{x_{t}}{p_{t}}\right) \quad \text { for } \quad \text { all } \quad t=0,1, \ldots
$$

The firm behavior is summarized by the set of price allocations $\Pi=\left\{p_{t}(i) \mid i \in\right.$ $[0,1] ; t=0,1, \ldots\}$.

A competitive equilibrium consists of a set of allocations $\{\Pi, \Omega\}$ that describes the equilibrium prices and quantities, given a set of monetary policy choices, obtained from (i) solving problem $(\mathrm{H})$ taking prices, wages and profits as given, $(i i)$ solving $(\Lambda)$ taking wages as given, and (iii) ensuring the appropriate market clearing conditions hold. ${ }^{3}$

Consequently, in order to obtain the conditions for a competitive equilibrium, first fix $x=\left\{x_{t} \mid t=0,1, \ldots\right\}$. Firm $i$ then, taking $w_{t}$ and $p_{t}$ as given, sets prices $p_{t}(i)$ according to

$$
p_{t}(i)=p_{t}=\frac{\theta}{(\theta-1)} w_{t} \quad \text { for all } t=0,1, \ldots
$$

Using this result and the market clearing conditions, the representative household, taking $d_{t}(i), w_{t}, R_{t}$ and $p_{t}$ as given, sets $\Omega_{t}$ such that (see Ireland (1997) for detail), ${ }^{4}$

$$
\begin{gathered}
c_{t}=n_{t}=x_{t} / p_{t} \\
w_{t}=\frac{1}{\beta}\left(x_{t} x_{t+1}\right)\left(\frac{x_{t+1}}{p_{t+1}}\right)^{-\alpha} \\
c_{t}=\frac{\beta(\theta-1)}{\theta x_{t+1}} c_{t+1}^{\alpha} .
\end{gathered}
$$

In Ireland (1997) the governmental structure comprises of a single unit, the central government, who sets $x=\left\{x_{t} \mid t=0,1, \ldots\right\}$. He shows that under commitment, the government maximizes the household's utility $U_{0}$ subject to the household and firms first order conditions (Ramsey Problem). That implies the government selects the growth rate of money supply to maximize consumption. Solving the differential equation (4) given $x$, one gets that the optimal choice is to set $x_{t}=\beta$, the lower bound for the money

\footnotetext{
${ }^{3}$ The market clearing conditions are $m_{t+1}=1, b_{t+1}=0$ and $\int_{0}^{1} c_{t}(i) \mathrm{d} i=y_{t}=n_{t}$.

${ }^{4}$ The transversality condition, $\lim _{t \rightarrow \infty} \beta^{t}\left(\lambda_{t}^{S B}+\lambda_{t}^{C I A}\right)=\lim _{t \rightarrow \infty} \beta^{t}\left(\frac{c_{t}^{\alpha}}{x_{t}}\right)=0$, where $\lambda^{S B}$ and $\lambda^{C I A}$ are the multipliers for the standard budget and cash in advance constraints respectively, is also imposed.
} 
growth rate constraint. Hence, the Ramsey outcome has $x_{t}=\beta$ and $R_{t}=1$ for all $t$.

Under discretion money supply is set sequentially after firms set prices, but before the household allocation is set. Due to the inefficient level of output generated by monopoly distortions the government will have the incentive to increase output through money injections, characterizing the time inconsistency nature of monetary policy. In this case the Ramsey outcome can only be sustained under trigger-type or reputation based equilibria.

We depart from Ireland (1997) modifying the governmental structure. The structure here comprises of two authorities: a central bank and a government.

The government is responsible for setting an initial delegation contract to the central bank at the beginning of the period. Following Jensen (1997), the government is then allowed to reappoint the central bank altering the initial contract, at a determined cost, after firms have set prices (the timing of the actions will be explored in more detail in section 4).

The initial delegation contract is summarized by the variable $f_{t}^{a} \geqslant 1$, which determines the cost of the central bank from setting the money supply growth rate greater than $\beta$. The reappointment contract is described by the parameter $f_{t} \geqslant 1$. If $f_{t}^{a}=f_{t}$, then the central bank is not reappointed while, if $f_{t}^{a} \neq f_{t}$, the central bank contract is altered at time $t$.

The reappointment decision is made to maximize the welfare of the representative household minus a penalty if the central bank is in fact reappointed. Thus, the government sets $\left\{f_{t}\right\}_{t=0}^{\infty}$ to maximize (problem (GR))

$$
V_{G}=\sum_{t=0}^{\infty} \beta^{t}\left[\frac{\left(c_{t}\right)^{\alpha}}{\alpha}-n_{t}-\varphi k\left(f_{t}, f_{t}^{a}\right)\right]
$$

taking $f_{0}^{a}$ and $p_{0}$ as given. $k($.$) is a reappointment cost function dependent on the$ delegation and reappointment parameters and $\varphi$, the reappointment cost parameter, determines the weight of the reappointment cost relative to the economy's welfare in the government's objective function.

The initial appointment decision is also made to maximize the welfare of the household, however, the decision is made before prices are set. As the government acts strategically it already predicts that it might reappoint the central bank in the future and takes that into account when setting the initial delegation parameter. Thus, the government delegation problem (GD) is

$$
\max _{\left\{f_{t}^{a}\right\}_{t=0}^{\infty}} \sum_{t=0}^{\infty} \beta^{t}\left[\frac{\left(c_{t}\right)^{\alpha}}{\alpha}-n_{t}-\varphi k\left(f_{t}, f_{t}^{a}\right)\right] .
$$


Define the government action at time $\mathrm{t}$ as $F_{t}=\left\{f_{t}^{a}, f_{t}\right\}$ and $F=\left\{F_{t} \mid t=0,1, \ldots\right\}$.

The central bank sets the actual monetary policy to maximize the representative household welfare minus a linear adjustment cost, delegated by the government, that punishes the central bank if the money supply is higher than the optimal commitment level $\left(x_{t}=\beta\right)$. Thus, the central bank's problem (CB) is to set $x=\left\{x_{t} \mid t=0,1, \ldots\right\}$ to maximize

$$
V_{C B}=\sum_{t=0}^{\infty} \beta^{t}\left[\frac{\left(c_{t}\right)^{\alpha}}{\alpha}-n_{t}-\frac{f_{t}-1}{p_{t}}\left(x_{t}-\beta\right)\right]
$$

taking the current period delegation, $f_{0}$, and prices, $p_{0}$, as given.

Assuming the central bank maximizes the period by period objective function ${ }^{5}$, which after incorporating the household's first order condition $(2)$ is given by $\left[\frac{\left(x_{t} / p_{t}\right)^{\alpha}}{\alpha}-\frac{x_{t}}{p_{t}}-\right.$ $\left.\frac{f_{t}-1}{p_{t}}\left(x_{t}-\beta\right)\right]$, the money growth rate at time $t=0,1, \ldots$ is set such that

$$
x_{t}=\left(f_{t}\right)^{\frac{1}{(\alpha-1)}} p_{t} \quad \text { for } \quad \beta \leqslant x_{t} \leqslant \bar{x} .
$$

The monetary policy choice of the entire governmental structure is, therefore, the set $\{x, F\}$.

\section{Delegation and Monetary Policy under Commitment}

Under commitment the government chooses a policy once and for all and then the household, the central bank and the firms make their decisions sequentially. Consequently, reappointments are not allowed, or the government can commit to appoint the central bank at time zero with delegation parameter $f^{*}=f_{t}^{a}=f_{t}$ for all $t=\{0,1, \ldots\}$. This is equivalent to the Ramsey Problem described in Ireland (1997), although the government here sets $F$ to maximize consumption and the household's utility instead of setting $x$ directly.

Accordingly, the commitment equilibrium consists of a policy $F$ and a set of allocation $\{x, \Pi, \Omega\}$ such that $F$ maximizes consumption given $\{x, \Pi, \Omega\}$; given $F$ and $\{\Pi, \Omega\}$, $x$ solves the central bank problem (CB); and given $\{x, F\},\{\Pi, \Omega\}$ is a competitive equilibrium.

\footnotetext{
${ }^{5}$ That might not be the best strategy for the central bank when maximizing $V_{C B}$. This is going to be analyzed in more detail when we discuss the two equilibrium conditions under discretion considered here, namely, sustainable equilibrium and Markov equilibrium.
} 
Combining (3) and (1), solving the resulting differential equation given $x$ and inputting the result into (5) we obtain that the money growth rate is such that

$$
\begin{aligned}
& \widetilde{x}=\left(f^{*}\right)^{(1 /(\alpha-1))} p=\left(f^{*}\right)^{(1 /(\alpha-1))}\left(\frac{(\theta-1) \beta}{\theta}\right)^{(1 /(\alpha-1))}\left(\underline{x}^{(2-\alpha) /(1-\alpha)}\right) \\
& \widetilde{x}=\left(f^{*}\right)\left(\frac{(\theta-1) \beta}{\theta}\right) .
\end{aligned}
$$

Thus, in order to ensure the central bank sets $\widetilde{x}=\beta$, the optimal choice to maximize consumption, the government must set $f^{*}=\frac{\theta}{(\theta-1)}$, which is equal to the monopoly mark-up. The intuition behind this result is straightforward. Higher mark-up levels imply greater inefficiency caused by the monopoly in the goods market, and therefore greater the temptation that a central bank would have to increase the money supply. In order to guarantee that the optimal monetary policy is achieved $\left(x_{t}=\beta\right)$ a greater punishment for a deviation from that policy must be imposed on the central bank, thus a greater delegation parameter $f^{*}$ is needed.

Note that although the central bank still plays sequentially and strategically, given $f_{t}=f^{*}=\frac{\theta}{(\theta-1)}$, it will not find it optimal to deviate from (5). Hence, (5) solves (CB). Finally, since the first order conditions of the household and firms problems have been incorporated into the central bank and government problems, the allocation set $\{\Pi, \Omega\}$ that implies $f^{*}$ and $x_{t}=\beta$ is a competitive equilibrium.

As a result, the Ramsey outcome presented in Ireland (1997) with $x_{t}=\beta$ and $R_{t}=1$ for all $t$ is also obtained here under commitment, although the commitment here is not on monetary policy making as in that paper, but on delegation or the institutional design decision. This shift relates directly to McCallum's (1995, 1997) criticism of delegation as a solution to the time inconsistency problem.

Note that the mark-up is greater than one satisfying the condition imposed for $f_{t}$. Also observe that having a microfounded model of time inconsistency leads to a better characterization of the linear contract (see Walsh (1995)) since the relationship between its parameters and the structural parameters of the economy has been established.

\section{Delegation, Reappointment and Monetary Policy under Discretion}

As in Chari and Kehoe (1990), lack of commitment is modeled by the following timing scheme. Each period $t$ is divided into five stages. In the first stage the government sets the initial delegation parameter. After that, firms set prices. The government is then allowed to reappoint the central bank. In stage four, the central bank sets the money supply growth rate or the actual monetary policy and finally the representative household sets its allocation. 
At the first stage of period $t$, the government, faced with a history $h_{t-1}=\left\{\left(x_{s}, F_{s}\right) \mid\right.$ $s=0, \ldots, t-1\}^{6}$, sets $f_{t}^{a}$. Let the government delegation rule be $\sigma_{1 t}\left(h_{t-1}\right)=f_{t}^{a}$. Firms, given the history $h_{t-1}$ and $f_{t}^{a}$, set prices for period $t$ in the second stage. Let the firms' pricing rule be given by $\pi\left(h_{t-1}, f_{t}^{a}\right)=p_{t}$ (note that as all firms are identical the subscript $i$ has been dropped). Given $h_{t-1}, f_{t}^{a}$ and $p_{t}$, the government sets the new contract parameter for time $t, f_{t}$. Let the reappointment rule be $\sigma_{2 t}\left(h_{t-1}, f_{t}^{a}, p_{t}\right)=f_{t}$. Following that, the central bank sets monetary policy given $h_{t-1}, f_{t}^{a}, p_{t}$ and $f_{t}$. Let the monetary policy rule be $\sigma_{3 t}\left(h_{t-1}, F_{t}, p_{t}\right)=x_{t}$.

The policy plans $\sigma_{1 t}, \sigma_{2 t}$ and $\sigma_{3 t}$ are then used to obtain future histories from $h_{t-1}$. Given the new history $h_{t}$, obtained from this process, the representative household decides its allocation. The allocation rule is given by $\Omega_{t}=\omega\left(h_{t}\right)$. Note that policy, price and allocation rules are used to obtain contingency plans for all possible histories. These contingent plans are then used by the players in order to determine their actions today when these depend on future variables (e.g. firms pricing decision). Finally, all players observe the aggregate outcomes, derived from $(\omega, \pi)$, that determine their payoff.

Let a policy plan $\sigma_{j}$ be equal to $\left(\sigma_{j 0}, \sigma_{j 1}, \ldots\right)$ for $j=\{1,2,3\}$ and denote $\sigma_{j}^{t}$ as the continuation of $\sigma_{j}$ at $t$. The same definitions apply for allocation rules $\pi$ and $\omega$.

A sustainable equilibrium consists of the set $\left(\sigma_{1}, \sigma_{2}, \sigma_{3}, \omega, \pi\right)$ that satisfy:

(i) given the policy plans $\left(\sigma_{1}, \sigma_{2}, \sigma_{3}\right)$ and allocation rule $(\pi)$, the continuation of $\omega$ solves the representative household problem $(\mathrm{H})$ from time $t$ onwards for every history $h_{t}$;

(ii) given the policy plans $\left(\sigma_{1}, \sigma_{2}, \sigma_{3}\right)$ and allocation rule $(\omega)$, the continuation of $\pi$ solves the firms problems $(\Lambda)$ from time $t$ onwards for every history $h_{t-1}$;

(iii) given the policy plans $\sigma_{2}$ and $\sigma_{3}$, and allocation rules $(\omega, \pi)$, the continuation of $\sigma_{1}$ solves the government initial delegation problem (GD) from time $t$ onwards for every history $h_{t-1}$;

(iv) the continuation of $\sigma_{2}$ solves the government reappointment problem (GR) from time $t$ onwards for every history $h_{t-1}$ given policy plans $\sigma_{1}$ and $\sigma_{3}$, allocation rules $(\omega, \pi)$, the initial delegation $f_{t}^{a}$, and the aggregate price $p_{t}$;

(v) given the policy plans $\left(\sigma_{1}, \sigma_{2}\right)$ and allocation rules $(\omega, \pi)$, the continuation of $\sigma_{3}$ solves the central bank problem (CB) from time $t$ onwards for every history $h_{t-1}$, given the delegation parameters $F_{t}=\left(f_{t}^{a}, f_{t}\right)$ and the aggregate price $p_{t}$, and;

(vi) the market clearing conditions hold.

\footnotetext{
${ }^{6}$ As in Chari and Kehoe (1990) and Ireland (1997) histories do not include households and firms decisions. This is equivalent to assuming that these players are anonymous or that they do not play strategically, but competitively.
} 
Starting from a history $h_{-1}=\varnothing$, a sustainable equilibrium induces a particular sequence of policy choices and allocations, or a set $\{x, \Pi, \Omega, F\}$. We name this set a sustainable outcome.

Another equilibrium concept will be used to aid the analysis of monetary policy under discretion $^{7}$. Based on the contribution of Albanesi, Chari, and Christiano (2003), we will also consider a Markov Equilibrium. In this case the government and the central bank problems are modified such that they maximize the value function of the household problem in a competitive equilibrium, $v_{H}\left(m_{t}, x_{t}\right)$, minus the current period adjustment cost, $\varphi k\left(f_{t}, f_{t}^{a}\right)$ for the government and $\frac{f_{t}-1}{p_{t}}\left(x_{t}-\beta\right)$ for the central bank. Formally, the government problems at stage 1 and stage 3 , and the central bank problem are, respectively

$$
\begin{array}{ll}
\max _{\left\{f_{t}^{a}\right\}} & {\left[v_{H}\left(1, x_{t}\right)-\varphi k\left(f_{t}, f_{t}^{a}\right)\right]} \\
\max _{\left\{f_{t}\right\}} & {\left[v_{H}\left(1, x_{t}\right)-\varphi k\left(f_{t}, f_{t}^{a}\right)\right]} \\
\max _{\left\{x_{t}\right\}} & {\left[v_{H}\left(1, x_{t}\right)-\frac{f_{t}-1}{p_{t}}\left(x_{t}-\beta\right)\right] .}
\end{array}
$$

A Markov outcome is a set $\{x, \Pi, \Omega, F\}$ such that $\{\Pi, \Omega\}$ is a competitive equilibrium, and the monetary policy choice of the entire governmental structure, $\left\{f_{t}^{a}, f_{t}, x_{t}\right\}$, solves (6), (7) and (8), respectively. A Markov equilibrium consists of a set of strategies for the government at stages 1 and 3 , for the central $b_{a n k}^{8}$, for the household, and for the firms that induces a Markov outcome.

Two properties of a Markov equilibrium should be highlighted. Firstly, in a competitive equilibrium, households take the set of future monetary policy choices $\{x, F\}_{t+1}^{\infty}$ as given. Hence, when the governmental structure maximizes $v_{H}\left(1, x_{t}\right)^{9}$ it also takes them as given. That is the reason only the current adjustment cost was included into the objective functions. Secondly, $\left\{f_{t}^{a}, f_{t}, x_{t}\right\}$ does not affect the discounted utility of the household starting from $t+1$, since it does not affect $x_{t+1}$. Therefore, in a Markov equilibrium both the government and the central bank maximize the current period utility $\left(\frac{c_{t}^{\alpha}}{\alpha}-n_{t}\right)$ minus its respective adjustment cost.

When setting out the model in section 2 the government reappointment and delegation problems were presented in their general form given that no functional form has been assumed for the reappointment cost function $k($.$) . As discussed in the introduction$ two different functional forms will be used: quadratic and absolute value.

\footnotetext{
${ }^{7}$ The relationship between the two equilibrium concepts used in the analysis will be explored in more detail in the next section.

${ }^{8}$ Note that these are different than $\left(\sigma_{1 t}, \sigma_{2 t}, \sigma_{3 t}\right)$ since for these the history, $h_{t-1}$, play a role.

${ }^{9}$ In a competitive equilibrium $m_{t}=m_{t+1}=1$.
} 


\subsection{Quadratic Reappointment Cost Function}

In order to compare our results to the results in Jensen (1997) and Driffill and Rotondi (2006) we start by assuming that the reappointment cost function is quadratic. That way, let $k\left(f_{t}, f_{t}^{a}\right)=\frac{\left(z_{t}-z_{t}^{a}\right)^{2}}{2}$, where $z_{t}^{a}=\left(f_{t}^{a}\right)^{(1 /(\alpha-1))}$ and $z_{t}=\left(f_{t}\right)^{(1 /(\alpha-1))}$.

The following two propositions establish the main results for the quadratic cost function case. The first proposition shows that under this specification the Markov equilibrium has $x_{t}=\beta$ for all $t$. In the second we show that any Markov equilibrium is also a sustainable equilibrium, hence, there also exists a sustainable equilibrium with $x_{t}=\beta$ for all $t$. Given that this sustainable equilibrium is also a Markov equilibrium, it is in fact supported without trigger-type strategies.

Proposition 1. The set $\{x, \Pi, \Omega, F\}$ where $x$ is such that $x_{t}=\beta, \Pi$ is such that $p_{t}=$ $\underline{p}=\beta\left(\frac{\theta}{(\theta-1)}\right)^{\frac{1}{(1-\alpha)}}, \Omega$ includes $c_{t}=\bar{c}=((\theta-1) / \theta)^{(1 /(1-\alpha))}$ and $F$ is such that $F_{t}=$ $\left(f_{t}^{a}, f_{t}\right)=\left(\left[\left(\frac{\theta}{\theta-1}\right)^{1 /(\alpha-1)}+\frac{1}{\varphi}-\frac{\theta}{(\theta-1) \varphi}\right]^{\alpha-1}, \frac{\theta}{\theta-1}\right)$ is a Markov outcome.

\section{Proof}

First note that given the decisions of the government and central bank, $\{\Pi, \Omega\}$ is a competitive equilibrium. Using, (3), (1) and $x_{t}=\beta$ for all $t, p_{t}=\underline{p}$ obtains, and using this result and $(2), c_{t}=\bar{c}$ obtains.

In a Markov equilibrium the central bank maximizes the current period payoff and sets monetary policy according to (5). Given $\{\Pi, \Omega\}$ and $f_{t}=\frac{\theta}{\theta-1}$, it is optimal for the central bank to set $x_{t}=\beta$.

The problem of the government at stage three using (2) and (5) becomes

$$
\max _{z_{t}}\left[\frac{\left(z_{t}\right)^{\alpha}}{\alpha}-z_{t}-\frac{\varphi}{2}\left(z_{t}-z_{t}^{a}\right)^{2}\right]
$$

which implies

$$
z_{t}^{\alpha-1}-\varphi z_{t}=1-\varphi z_{t}^{a}
$$

Using (9) and initial delegation $f_{t}^{a}=\left[\left(\frac{\theta}{\theta-1}\right)^{1 /(\alpha-1)}+\frac{1}{\varphi}-\frac{\theta}{(\theta-1) \varphi}\right]^{\alpha-1}$, it is optimal for the government to set $f_{t}=\frac{\theta}{\theta-1}$.

Finally, at stage one the government must decide the delegation parameter $f_{t}^{a}$. If firms equilibrium prices are given by (3) and (1), the central bank decides monetary policy according to (5) and the reappointment decision is made according to (9), then

$$
p_{t}=\left[\frac{\theta}{(\theta-1) \beta}\right]^{\frac{1}{(1-\alpha)}}\left(z_{t} p_{t}\right)^{\frac{2-\alpha}{1-\alpha}}=\frac{(\theta-1) \beta}{\theta} z_{t}^{\alpha-2} .
$$

From (5)

$$
x_{t}=z_{t} p_{t}=\frac{(\theta-1) \beta}{\theta}\left(z_{t}^{\alpha-1}\right) .
$$


As $\beta \leqslant x_{t} \leqslant \bar{x}$, then it follows that

$$
\left(\frac{\theta \bar{x}}{(\theta-1) \beta}\right)^{(1 /(\alpha-1))} \leqslant z_{t} \leqslant\left(\frac{\theta}{(\theta-1)}\right)^{(1 /(\alpha-1))}
$$

Consequently, when taking as given the firms and household allocation rules, the central bank's policy rule and its own reappointment rule, the government's delegation problem under Markov equilibrium becomes to maximize $\left[\frac{\left(z_{t}\right)^{\alpha}}{\alpha}-z_{t}-\frac{\varphi}{2}\left(\frac{\left(z_{t}^{\alpha-1}-1\right)}{\varphi}\right)^{2}\right]$ subject to (11).

Given $0<\alpha<1$, the government's objective function is increasing in $z_{t}$. As $z_{t}$ is bounded above by $\left(\frac{\theta}{(\theta-1)}\right)^{(1 / \alpha-1)}$ (see (11)), it is optimum to set $z_{t}^{a}$ such that $z_{t}=$ $\left(\frac{\theta}{(\theta-1)}\right)^{(1 / \alpha-1)}$ or $f_{t}=\frac{\theta}{(\theta-1)}$. Plugging that back into (9) gives

$$
f_{t}^{a}=\left[\left(\frac{\theta}{\theta-1}\right)^{1 /(\alpha-1)}+\frac{1}{\varphi}-\frac{\theta}{(\theta-1) \varphi}\right]^{\alpha-1} \text {. }
$$

Proposition 2. The Markov equilibrium is also a sustainable equilibrium. ${ }^{10}$

\section{Proof}

The proof is a direct implication of the one-stage deviation principle, which can be applied here since $(i)$ the actions of the players who play strategically are observed; and (ii) given that payoffs are discounted and the fact that per-period payoffs are bounded, the game is continuous at infinity (see Fudenberg and Tirole (1991), Chapter 4). Given $\{\Pi, \Omega\}$, both the government and the central bank would not deviate from the strategy that delivers a Markov equilibrium, given a history $h_{t-1}$ that confirms this equilibrium, since a deviation would lower their current period payoffs. Finally, given $\{x, F\},\{\Pi$, $\Omega\}$ is a competitive equilibrium, thus markets clear and $(\pi, \omega)$ solve the household and firms problems.

Propositions 1 and 2 show that the government will set a higher delegation parameter than the optimal commitment parameter, which is equal to the mark-up, and after the pricing decision is made, it will reappoint the central bank setting the reappointment parameter equal to the mark-up. That way, the Ramsey outcome is achieved without a commitment technology. However, due to the lack of commitment technology the government's objective function is reduced as the central bank is constantly reappointed. As we have seen, under commitment, $f^{a}=f$, hence this equilibrium under discretion does not yield the same utility for the government as in the commitment case, but yields the same utility for the household and central bank, or the same set $\{x, \Pi, \Omega\}$.

This result is similar to the result obtained by Driffill and Rotondi (2006) where the government sets the initial appointment parameter higher than the optimal commitment

\footnotetext{
${ }^{10}$ Note that proposition 2 does not characterize all sustainable equilibria, hence there may exist other equilibria with $x_{t}=\beta$ for all $t$.
} 
level and reappoints the central bank by resetting the parameter to the optimal commitment level. Using this strategy the reputation equilibrium with no inflation bias is achieved for economies for which it was not possible to do so without delegation. However, in the model presented here, this strategy not only resolves the time inconsistency problem for economies with a high discount rate, but for all economies, independent of the discount rate. As opposed to their's, the equilibrium here is sustained without the support of trigger-type/reputation strategies or it is a Markov as well as a sustainable equilibrium.

The stronger result arises since in Driffill and Rotondi's (2006) model the announcement of a more rigorous central bank contract is not able to offset the government's temptation to reappoint a lenient central bank (i.e. less conservative than the one needed to deliver the commitment outcome). Hence, the announcement only makes the reputation equilibrium more likely to be sustained. In the model presented here the optimal delegation parameter $\left(f^{a}\right)$ is such that it eliminates the government's incentive to reappoint a central bank who would set the money supply growth rate above the commitment level. Consequently, the fact that the government moves first, setting the delegation parameter, sufficiently restricts its next move, the reappointment, such that the final central bank's contract completely offsets the incentive to increase output ex-post.

In fact a Markov equilibrium in the Driffill and Rotondi's (2006) model delivers a delegation parameter $\left(f^{a}\right)$ that is smaller than the one required to ensure that the commitment equilibrium is achieved. Thus, inflation is positive. As $f^{a}$ decreases, the decrease in reappointment costs outweighs the positive effect on inflation, increasing the government's payoff. In the model here this is not the case; decreasing $f^{a}$ from its Markov equilibrium level also lowers reappointment costs, but aggregate prices increase such that the government's payoff is lower. This result obtains due to the fact that an equilibrium where prices are set based on an expected money supply growth rate that is confirmed by the central bank only occurs at the two boundaries of the money supply growth process. Hence, there could only exist two Markov equilibria, one with a high growth rate $(x=\bar{x})$ and one with a low $(x=\beta)$. Delegation is able to move the economy from the high inflation/money growth equilibrium to the lower one. The occurrence of two Markov equilibria, one with high and one with a low inflation, is also emphasized by Albanesi, Chari, and Christiano (2003). They show that the absence of commitment leads to multiple equilibria or expectation traps. Thus, the introduction of delegation and costly reappointment can eliminate the trap, leading the economy to the unique low inflation equilibrium.

Despite resolving the time inconsistency problem the set up with quadratic reappointment costs has the unfortunate and unrealistic result that central banks would be constantly reappointed. It follows from (9) that as $\varphi \rightarrow \infty, z_{t} \rightarrow z_{t}^{a}$. Thus, if the reappointment parameter $\varphi$ is bounded the government will always find it optimum to reappoint the central bank. Formally, if $\varphi<\infty$, then $z_{t}>z_{t}^{a}$ and $f_{t}<f_{t}^{a}$. That occurs because quadratic reappointment cost functions are smooth, thus there will always be a 
gain, however small, in reappointing. A more realistic assumption would be that when $f_{t}=f_{t}^{a}-\xi$, there will be a small jump in the reappointment cost (similar to a fixed cost of reappointment), or that the marginal cost of reappointing when $f_{t}=f_{t}^{a}$ is not equal to zero. An absolute value reappointment cost function would have this characteristic and, as it is shown in the next section, where this functional form is assumed, constant reappointments do not happen.

\subsection{Absolute Value Reappointment Cost Function}

Let $k\left(f_{t}, f_{t}^{a}\right)=z_{t}^{a}\left|\left(z_{t}-z_{t}^{a}\right)\right|$, where as before $z_{t}^{a}=\left(f_{t}^{a}\right)^{(1 /(\alpha-1))}, z_{t}=\left(f_{t}\right)^{(1 /(\alpha-1))}$.

Under a Markov economy the government reappointment problem, using (2) and the central bank optimal policy (5), becomes

$$
\max _{\left\{z_{t}\right\}}\left[\frac{\left(z_{t}\right)^{\alpha}}{\alpha}-z_{t}-\varphi z_{t}^{a}\left|\left(z_{t}-z_{t}^{a}\right)\right|\right] .
$$

That gives the following first order condition.

$$
\begin{array}{ll}
z_{t} & =\left(1+\varphi z_{t}^{a}\right)^{\left(\frac{1}{\alpha-1}\right)} \quad \text { if } \quad z_{t}>z_{t}^{a} \\
z_{t} & =z_{t}^{a} \quad \text { otherwise. }
\end{array}
$$

Due to the discontinuity of the objective function at $z_{t}=z_{t}^{a}$ one must check if the above first order condition actually gives the maximum of the objective function. Given that $f_{t}^{a} \geqslant 1, f_{t} \geqslant 1$ and $0<\alpha<1, z_{t}^{a}$ must lie in $[0,1]$ and so must $z_{t}$. As the first two terms of the objective function are together increasing in $z_{t}$ then one must have that either it is optimal to set $z_{t}=z_{t}^{a}$ (case 1) or to set $z_{t}>z_{t}^{a}$ (case 2), depending on the reappointment cost parameter $\varphi$ and the delegation parameter $f_{t}^{a}$. Also note that for both cases it is necessary that $\beta \leqslant x_{t} \leqslant \bar{x}$, given that the first order condition of the central bank's problem has been used into the government's reappointment problem.

\subsubsection{Case $1-z_{t}=z_{t}^{a}$}

Given the values of $\varphi$ and $f_{t}^{a}$, the welfare gain from a higher money supply growth might not be greater than the reappointment cost the government must pay. The government's optimal decision would then be to maintain the central bank's contract, setting $f_{t}=f_{t}^{a}$. Proposition 3 establishes that there is a bounded value of $\varphi$, function of $f_{t}^{a}$, for which this is the case.

Proposition 3. For every $1 \leqslant f_{t}^{a} \leqslant M<\infty$ there will be a $\varphi<\infty$ such that maintenance of the central bank is optimal.

(See the appendix for the proof). 
The following proposition establishes the main result for Case 1 with an absolute value cost function. It shows that under this specification the commitment equilibrium is also a Markov and a sustainable equilibrium.

Proposition 4. The set $\{x, \Pi, \Omega, F\}$ where $x$ is such that $x_{t}=\beta, \Pi$ is such that $p_{t}=$ $\underline{p}=\beta\left(\frac{\theta}{(\theta-1)}\right)^{\frac{1}{(1-\alpha)}}, \Omega$ includes $c_{t}=\bar{c}=((\theta-1) / \theta)^{(1 /(1-\alpha))}$ and $F$ is such that $F_{t}=$ $\left(f_{t}^{a}, f_{t}\right)=\left(\frac{\theta}{\theta-1}, \frac{\theta}{\theta-1}\right)$ for all $t$ is a sustainable and a Markov outcome if $\varphi>\frac{\left(\frac{\theta}{\theta-1}-1\right)}{\left(\frac{\theta}{\theta-1}\right)^{1 / \alpha-1}}$.

\section{Proof}

The proof here follows the same procedure as the one adopted for propositions 1 and 2, first establishing that the commitment outcome listed above is a Markov outcome and then using that to prove it is also a sustainable outcome. Using (3), (1) and $x_{t}=\beta$ one obtains that $p_{t}=p$ and using this result and (2) one obtains that $c_{t}=\bar{c}$. If the central bank is given a contract with $f_{t}=\frac{\theta}{\theta-1}$, then it is optimal to set $x_{t}=\beta$ (see (5)). At stage three, given the initial delegation $f_{t}^{a}=\frac{\theta}{\theta-1}$, and assuming $\varphi>\frac{\left(f_{t}^{a}-1\right)}{\left(f_{t}^{a}\right)^{1 / \alpha-1}}$, it is optimal for the government to set $f_{t}$ according to (12), thus setting $f_{t}=f_{t}^{a}$.

Finally, at stage one the government must decide the delegation parameter $f_{t}^{a}$ to maximize $\left(\frac{c_{t}^{\alpha}}{\alpha}-n_{t}\right)-z_{t}^{a}\left|\left(z_{t}-z_{t}^{a}\right)\right|$. If firms equilibrium prices are given by (3) and (1), the central bank decides monetary policy according to (5) and the reappointment decision is made according to (12), then

$$
x_{t}=\left(f_{t}^{a}\right)^{1 /(\alpha-1)} p_{t}=\frac{(\theta-1) \beta}{\theta}\left(f_{t}^{a}\right) .
$$

As $\beta \leqslant x_{t} \leqslant \bar{x}$, then it follows that $\frac{\theta}{(\theta-1)} \leqslant f_{t}^{a} \leqslant \frac{\theta \bar{x}}{(\theta-1) \beta}$.

Therefore, when taking as given the firms and household allocation rules, the central bank's policy rule and its own reappointment rule the government delegation problem translates into maximizing household's consumption subject to (13) and the constraint on $f_{t}^{a}$. Hence,

$$
\max _{f^{a}} c=\max _{f^{a}}\left(\frac{(\theta-1) \beta}{\theta x}\right)^{1 /(1-\alpha)}=\max _{f^{a}}\left(\frac{1}{f^{a}}\right)^{1 /(1-\alpha)}
$$

subjected to $\frac{\theta}{(\theta-1)} \leqslant f_{t}^{a} \leqslant \frac{\theta \bar{x}}{(\theta-1) \beta}$.

Given that the objective function in the maximization problem is decreasing in $f^{a}$, it is optimal to set $f^{a}=\theta /(\theta-1)$, the lower bound of the constraint. Following the same argument as proposition 2 the Markov outcome is also a sustainable outcome.

Proposition 4 formalizes Persson and Tabellini's (1999) conjecture that a high cost of changing the institution should be enough to answer McCallum's $(1995,1997)$ criticism. In the set up presented here, if $\varphi>(\theta /(\theta-1)-1) /(\theta /(\theta-1))^{1 / \alpha-1}$, then the commitment solution is achieved though no commitment technology has been assumed on the government's institutional design decision. The equilibrium in this dynamic optimization 
problem is sustained without the support of trigger-type or reputation based strategies, being applicable to all economies independent of their discount factors.

As in the quadratic reappointment cost case, the introduction of delegation as a first move is enough to prevent the governmental structure from inflating the economy expost. The driver of the result in this case, however, is that the government's objective function is not continuous, reflecting the fact that reappointment might carry a fixed cost, and there exists a level (bounded) where reappointment costs are prohibitively high such that no reappointment is done and the commitment solution is achieved.

\subsubsection{Case $2-z_{t}>z_{t}^{a}$}

The values of $\varphi$ and $f_{t}^{a}$ might be such that the government finds it optimal to set $f_{t}<f_{t}^{a}$ and reappoint the central bank. Following proposition 3, this is the case when $\varphi<\frac{f_{t}^{a}-1}{\left(f_{t}^{a}\right)^{1 / \alpha-1}}$.

In this case the characterization of the sustainable equilibrium will be done following Chari and Kehoe (1990) and Ireland (1997) more closely. First consider the static or autarky outcome given by $\left\{x^{A}, \Pi^{A}, \Omega^{A}, F^{A}\right\}$ where $x^{A}$ is such that $x_{t}=\bar{x}, \Pi^{A}$ is such that $p_{t}=\bar{p}=\left(\frac{\theta}{(\theta-1) \beta}\right)^{\frac{1}{(1-\alpha)}} \bar{x}^{(2-\alpha) /(1-\alpha)}, \Omega^{A}$ includes $c_{t}=\underline{c}=((\theta-1) \beta / \theta \bar{x})^{(1 /(1-\alpha))}$ and $F^{A}$ is such that $F_{t}=\left\{f_{t}^{a}, f_{t}\right\}=\{1,1\}$ for all $t$. Let $\left(\sigma_{1}^{A}, \sigma_{2}^{A}, \sigma_{3}^{A}, \omega^{A}, \pi^{A}\right)$ be the set of policy and allocation rules that induce the autarky outcome.

Proposition 5. The autarky equilibrium is a Markov Equilibrium, and therefore, a sustainable equilibrium.

The formal proof of this statement is given in the appendix, but the intuition is simple and will be provided here. As the central bank is always reappointed to a less conservative central bank than the one that would deliver the commitment money supply growth rate, the central bank will always have the incentive to inflate the economy. That way, if firms expect $x_{t}=x^{e}$, setting prices accordingly, the central bank will set $x_{t}$ slightly higher than $x^{e}$, boosting output. As firms increase their expectation so does the actual policy set by the central bank. Expectations only catch up with actual policy when $x^{e}=\bar{x}$. The central bank would find it optimum to increase $x_{t}$ further, but is prevented from doing so by its constraint, thus setting $x_{t}=\bar{x}$. In the limit as $\bar{x}$ becomes arbitrarily large $c_{t}=n_{t}$ approaches zero.

Proposition 6. The autarky equilibrium is the worst sustainable equilibrium for all players.

Again, the formal proof of this statement is presented in the appendix, with only a discussion provided here. Given that under autarky the total payoff of each player - the 
government, the firms, the household and the central bank - approaches zero, one only needs to prove that in any sustainable equilibrium both the government and the central bank will not have negative total utility (welfare and profits are non-negative under a competitive equilibrium). We show that must be the case since a strategy for either the government or the central bank that delivers a current discounted sum of payoffs that is negative is not optimal, invalidating conditions (iv) and (v) of a sustainable equilibrium.

We are now ready to apply the Chari and Kehoe's (1990) technique, adapted from Abreu (1988), to characterize the sustainable outcomes induced by reverting-to-autarky plans. For an arbitrary sequence of policies and allocation rules $\left(\sigma_{1}^{S}, \sigma_{2}^{S}, \sigma_{3}^{S}, \omega^{S}, \pi^{S}\right)$ the revert to autarky plan determines that players will continue playing according to these policies as long as they have been selected by all players in the past. If any player deviates, then each other player will maximize their current period payoff for the remaining stages of the deviation period and will play the autarky policies and allocation rules $\left(\sigma_{1}^{A}, \sigma_{2}^{A}, \sigma_{3}^{A}, \omega^{A}, \pi^{A}\right)$ in all subsequent periods. This gives rise to the following proposition established in the appendix.

Proposition 7. The set $\{\widehat{x}, \widehat{\Pi}, \widehat{\Omega}, \widehat{F}\}$ is a sustainable outcome if and only if

(i) $\{\widehat{\Pi}, \widehat{\Omega}\}$ is a competitive equilibrium

(ii) $\{\widehat{x}, \widehat{\Pi}, \widehat{\Omega}, \widehat{F}\}$ satisfies the following two inequalities for every $t$

(a) $\quad V_{G}^{S} \geqslant U_{t}^{d}+\beta V_{G}^{A}$

(b) $\quad V_{C B}^{S} \geqslant C B_{t}^{d}+\beta V_{C B}^{A}$

where $V_{G}^{S}$ and $V_{C B}^{S}$ equal to the total utility under the sustainable equilibrium from time $t$ onwards, $U_{t}^{d}$ and $C B_{t}^{d}$ equal to the gain from deviating from the sustainable equilibrium strategy in the current period ( $t)$ and $V_{G}^{A}$ and $V_{C B}^{A}$ equal to the total utility under the autarky equilibrium from time $t+1$ onwards, for the government and the central bank, respectively.

Note that this general characterization of sustainable outcomes incorporates all possible outcomes including the ones established in propositions 2 and 4 . However, in these two cases we did not need a revert-to-autarky or a trigger strategy since we showed that the sustainable equilibrium is also a Markov equilibrium. This is equivalent to the assertion that, for these two cases, the utility from any possible deviation, $\left(U_{t}^{d}\right.$ and $\left.C B_{t}^{d}\right)$, are not greater than the government's and central bank's current period utility under the sustainable equilibria obtained there.

Given this general characterization of sustainable outcomes one can now verify under what conditions the commitment equilibrium is sustainable. The commitment outcome, as shown in section 3 , is $c_{t}=n_{t}=\bar{c}, x_{t}=\beta, p_{t}=p=\beta(\theta /(\theta-1))^{1 /(1-\alpha)}$ and $f_{t}^{a}=f_{t}=(\theta /(\theta-1))$. That way, $V_{G}^{S}=\frac{1}{1-\beta}\left(\frac{\bar{c}^{\alpha}}{\alpha}-\bar{c}\right)$. Under autarky the utility is given by $V_{G}^{A}=\frac{1}{1-\beta}\left(\frac{\underline{c}^{\alpha}}{\alpha}-\underline{c}\right)$. Note that the reappointment cost term does not enter in either 
$V_{G}^{S}$ or $V_{G}^{A}$ since $f_{t}^{a}=f_{t}$ in both cases.

Finally, the gain from deviation, $U_{t}^{d}$, is equal to

$$
\left[\frac{\left(z_{t}\right)^{\alpha}}{\alpha}-z_{t}-\varphi z_{t}^{a}\left|\left(z_{t}-z_{t}^{a}\right)\right|\right]
$$

where $z_{t}$ is set according to (12). Therefore, the following inequality must hold in order to ensure that the government does not deviate (applying $(a)$ in Proposition 7)

$$
\frac{1}{1-\beta}\left(\frac{\bar{c}^{\alpha}}{\alpha}-\bar{c}\right) \geqslant\left[\frac{\left(z_{t}\right)^{\alpha}}{\alpha}-z_{t}-\varphi z_{t}^{a}\left|\left(z_{t}-z_{t}^{a}\right)\right|\right]+\frac{\beta}{1-\beta}\left(\frac{\underline{c}^{\alpha}}{\alpha}-\underline{c}\right) .
$$

As Ireland (1997) shows, in the absence of a central bank, the Ramsey outcome, with $c_{t}=\bar{c}, x_{t}=\beta$ and $p_{t}=\underline{p}=\beta(\theta /(\theta-1))^{1 /(1-\alpha)}$ is sustainable if

$$
\frac{1}{1-\beta}\left(\frac{\bar{c}^{\alpha}}{\alpha}-\bar{c}\right) \geqslant\left(\frac{1}{\alpha}-1\right)+\frac{\beta}{1-\beta}\left(\frac{\underline{c}^{\alpha}}{\alpha}-\underline{c}\right) .
$$

Given $0<z_{t}<1$ and $z_{t}>z_{t}^{a}$, for any $\beta$ the right-hand side of (14) is smaller than the right-hand side of (15). Therefore, the introduction of a central bank, delegation of monetary policy and costly reappointment relaxes the requirement for the commitment equilibrium to be sustainable. In other words, the commitment equilibrium with the new governmental structure is sustained for a wider range of discount factors than the Ramsey equilibrium in Ireland (1997).

Two important points must be highlighted. First, if the commitment outcome is a candidate for a sustainable equilibrium we do not need to consider inequality $(b)$ because, given $f_{t}=\frac{\theta}{\theta-1}$, the best possible response for the central bank at period $t$ is to set $x_{t}=\beta$, confirming the sustainable outcome. In other words, $C B_{t}^{d}$ is not an improvement on the payoff of $V_{C B}^{S}$ at time $t$. Second, an important property of the revert-to-autarky plan is that a government deviation triggers autarky. Thus, if the government deviates in period $t$ at stage 3 , the central bank, who acts at stage 4 will maximize its period $t$ payoff, setting monetary policy according to (5), reverting to $x=\bar{x}$ for the subsequent periods. That way, the deviation is "confirmed" by the central bank and the actual monetary policy is set such that $x_{t}=z_{t} p_{t}$. We used this result in order to determine $U_{t}^{d}$.

The result in this case contrasts to the results in Jensen (1997). While the introduction of delegation has a negative effect on the gains from deviation in both models, it does not have the same effect on the punishment, which decreases in Jensen's (1997) model, but does not decrease here; the autarky equilibrium is the same in both cases. Jensen (1997) argues that due to this reduction in punishment the credibility of monetary policy in his model, understood as the ability of the governmental structure (government plus central bank) to sustain a reputational equilibrium, actually decreases. In the microfounded framework presented here delegation improves credibility. 
The main driver of this result is the property of our model that a Markov equilibrium only occurs at the boundaries of the money process. As proposition 5 in the appendix shows, when the government maximizes its period by period payoff and the reappointment cost is smaller than a specific threshold, there is no optimal $f^{a}$ that would induce prices being set based on an expected monetary policy that is actually confirmed by the central bank apart from $x_{t}=\bar{x}$. The central bank would always have the incentive to increase the money supply growth rate and, without commitment, firms expect $x_{t}=\bar{x}$ for all $t=\{0,1, \ldots\}$. In this case, with a low $\varphi$, the only Markov equilibrium is with a high money growth rate irrespective of whether delegation and an independent central bank are present or not. Therefore, under this framework, delegation can not eliminate the time inconsistency problem, but it makes the reputational equilibrium more likely to be sustained ${ }^{11}$.

As it was pointed out, under the framework presented above a government deviation triggers autarky. Alternatively, assume that the revert-to-autarky trigger would only be done if $x_{t} \neq x^{S}$, without considering the government action $F_{t}$. Under this plan, one must verify whether after the government's deviation at stage 3 , the central bank would move away from the candidate sustainable outcome at stage 4, "confirming" the deviation, or if the central bank would nevertheless adopt the sustainable policy. That would not be optimal at period $t$, but could deliver a higher utility from period $t$ onwards. This additional condition to sustainability could be formally introduced into proposition 7 by including a constraint that the central bank will not find it optimal to "confirm" the deviation should the government decide to do so.

This constraint states that the utility from "confirming" the deviation, maximizing the payoff at time $t$ and receiving the autarky payoff thereafter, is smaller than playing the sustainable policy even after the government's deviation, receiving a lower payoff at period $t$, but guaranteeing the greater payoff under the sustainable outcome thereafter. Formally

$$
\begin{aligned}
C B_{N C o n f}+\beta V_{C B}^{S} & \geqslant C B_{C o n f}+\beta V_{C B}^{A} \text { or } \\
V_{C B}^{S} & \geqslant\left[C B_{C o n f}-\left(V_{C B}^{S}-C B_{N C o n f}\right)\right]+\beta V_{C B}^{A}
\end{aligned}
$$

where $C B_{\text {Conf }}$ is the period $t$ central bank payoff if it "confirms" the deviation, maximizing the payoff at period $t$ and $C B_{N C o n f}$ the payoff if it plays the sustainable policy after the government's deviation.

Observe that under commitment, $V_{G}^{S}=V_{C B}^{S}=V^{S}$ and under autarky, $V_{C B}^{A}=V_{C B}^{A}=$ $V^{A}$. The government will deviate from the commitment outcome only if $V^{S}<U^{d}+\beta V^{A}$. The central bank will "confirm" the deviation if $V^{S}<\left[C B_{C o n f}-\left(V^{S}-C B_{N C o n f}\right)\right]+\beta V^{A}$. Therefore, if $U_{d}>\left[C B_{C o n f}-\left(V^{S}-C B_{N C o n f}\right)\right]$, then the modification of the trigger

\footnotetext{
${ }^{11}$ Note that in this case the government can not relax the sustainable equilibrium requirement (inequality $(a))$ by setting $f^{a}>(\theta /(\theta-1))$ and then setting $f=(\theta /(\theta-1))$. This strategy does not deliver a sustainable equilibrium. A formal proof of this results is available from the author upon request.
} 
strategy makes deviations less likely to occur or the requirements for the commitment equilibrium to be sustainable are relaxed. Hence, under this modified trigger strategy the existence of an independent central bank may prevent the government from deviating.

\section{Conclusion}

This paper analyzes the effectiveness of delegation as a device employed to overcome the time inconsistency problem of monetary policy. In order to do so we develop a microfounded general equilibrium model of time inconsistency, modeling explicitly the choice of delegation, reappointment, monetary policy and allocations as an interaction between two big players, the government and the central bank, who behave strategically and a large number of small players, the agents, who behave competitively. We conclude that delegation solves or mitigates the time inconsistency problem, countering McCallum's (1995) second fallacy.

By explicitly modeling the use of a monetary instrument and assuming equal preferences, reappointment costs aside, for the government and the representative household, the work presented here refutes the claim that delegation does not help in improving the credibility to sustain the commitment solution, asserting that it actually removes the time inconsistency when a quadratic reappointment cost is assumed. This result is stronger than the one obtained by Driffill and Rotondi (2006), since the equilibrium is obtained without reputation based strategies. Nonetheless, in both frameworks, the government is forced to constantly reappoint the central bank. This is the case since, due to the smoothness of the quadratic cost function, there is always a gain for the government, however small, to deviate.

When an absolute value reappointment cost function is assumed, there is a positive marginal cost for any small deviation. This functional form provides a better approximation since one might expect that any reappointment carries a non-neglectable cost. Under this assumption, if reappointment costs are smaller than a specific threshold, dependent on the level of monopoly distortion in the economy, then the time inconsistency problem is not removed, but the introduction of delegation and possible reappointment leads to the commitment equilibrium to be sustained for economies it was not possible to do so in their absence. On the other hand, if the reappointment cost is bigger than that threshold, then by moving first, setting the initial central bank contract, the government is able to restrict its own second move (reappointment) such that the central bank's incentive to inflate is completely offset. Hence, in our analysis, contrasting to the results in Driffill and Rotondi (2006), the time inconsistency problem is eliminated and the central bank is not constantly reappointed.

Based on the results presented here, therefore, it is of considerable importance to study the link between the monetary policy design and reappointment costs, which in 
most cases are reputation cost, but can also be political costs. One way of formalizing these costs is to consider the implied welfare costs of reappointment. In an interesting contribution to monetary policy under commitment and discretion, Schaumburg and Tambalotti (2007) assume that the central bank can effectively be reappointed with an exogenously determined probability $(\alpha)$. Upon being reappointed the central bank sets a new policy plan, reneging its predecessor promises. The existence of this possibility of reappointment decreases welfare. A possible link would be to consider this welfare costs as an approximation to the reappointment cost faced by the government when replacing the central bank, endogeneising $\alpha$. This way, given the state of the economy and the welfare costs of reappointing the central bank, which would lead to an increase in $\alpha$, the government decides at each period if the central bank should be maintained or not.

\section{References}

Abreu, D. (1988): "On the Theory of Infinitely Repeated Games with Discounting," Econometrica, 56(2), 383-96.

Albanesi, S., V. V. Chari, and L. J. Christiano (2003): "Expectation Traps and Monetary Policy," Review of Economic Studies, 70(4), 715-741.

BARro, R. J., ANd D. B. Gordon (1983): "Rules, discretion and reputation in a model of monetary policy," Journal of Monetary Economics, 12(1), 101-121.

Chari, V. V., and P. J. Kehoe (1990): "Sustainable Plans," Journal of Political Economy, 98(4), 783-802.

Driffill, J., And Z. Rotondi (2006): "Credibility of Optimal Monetary Delegation: Comment," American Economic Review, 96(4), 1361-1366.

Fudenberg, D., And J. Tirole (1991): Game Theory. The MiT Press.

Ireland, P. N. (1997): "Sustainable monetary policies," Journal of Economic Dynamics and Control, 22(1), 87-108.

Jensen, H. (1997): "Credibility of Optimal Monetary Delegation," American Economic Review, 87(5), 911-20.

Kydland, F. E., and E. C. Prescott (1977): "Rules Rather Than Discretion: The Inconsistency of Optimal Plans," Journal of Political Economy, 85(3), 473-91.

McCallum, B. T. (1995): "Two Fallacies Concerning Central-Bank Independence," American Economic Review, 85(2), 207-11.

MCCallum, B. T. (1997): "Crucial issues concerning central bank independence," Journal of Monetary Economics, 39(1), 99-112. 
Persson, T., and G. Tabellini (1999): "Political economics and macroeconomic policy," in Handbook of Macroeconomics, ed. by J. B. Taylor, and M. Woodford, vol. 1 of Handbook of Macroeconomics, chap. 22, pp. 1397-1482. Elsevier.

Rogoff, K. (1985): "The Optimal Degree of Commitment to an Intermediate Monetary Target," The Quarterly Journal of Economics, 100(4), 1169-89.

Schaumburg, E., And A. TAmbalotti (2007): "An investigation of the gains from commitment in monetary policy," Journal of Monetary Economics, 54(2), 302-324.

Svensson, L. E. O. (1997): "Optimal Inflation Targets, "Conservative" Central Banks, and Linear Inflation Contracts," American Economic Review, 87(1), 98-114.

Walsh, C. E. (1995): "Optimal Contracts for Central Bankers," American Economic Review, 85(1), 150-67.

\section{Appendix}

\section{Proof of Proposition 3.}

In a Markov economy if the central bank is not reappointed, then the government objective function (current period household's utility plus the current period reappointment cost) must be decreasing for $z_{t}>z_{t}^{a}$ (and the kink of the absolute value function is the solution to the maximization problem). Thus,

$$
\begin{gathered}
\left(z_{t}\right)^{\alpha-1}-1-\varphi z_{t}^{a}<0 \\
\varphi>\frac{\left(z_{t}\right)^{\alpha-1}-1}{z_{t}^{a}} .
\end{gathered}
$$

As $\left(z_{t}\right)^{\alpha-1}$ is decreasing in $z_{t}$ and $z_{t}>z_{t}^{a}$

$$
\varphi>\frac{\left(z_{t}^{a}\right)^{\alpha-1}-1}{z_{t}^{a}} .
$$

Given the definition of $z_{t}^{a}$ reappointment does not occur if

$$
\varphi^{*}>\frac{\left(f_{t}^{a}-1\right)}{\left(f_{t}^{a}\right)^{1 / \alpha-1}} .
$$

Finally as $1 \leqslant f_{t}^{a} \leqslant M<\infty$ then there exist a bounded $\varphi$, where $\infty>\varphi>\frac{(M-1)}{M^{1 / \alpha-1}}$, for which there is no reappointment.

\section{Proof of Proposition 5.}

Let $f_{t}^{a}=\theta /(\theta-1)$.

Using the government reappointment decision in a Markov economy, (12), one has that

$$
\left(1+\varphi\left(f_{t}^{a}\right)^{(1 /(\alpha-1))}\right)=\bar{f}_{t}<\theta /(\theta-1) .
$$


Differentiating that with respect to $f_{t+s}^{a}$ gives

$$
\frac{\partial f_{t}}{\partial f_{t}^{a}}=\frac{\varphi}{(\alpha-1)}\left(f_{t}^{a}\right)^{\frac{2-\alpha}{\alpha-1}}<0 .
$$

Therefore, as $f_{t}^{a}$ increases from $f_{t}^{a}=\theta /(\theta-1), f_{t}$ decreases from $\bar{f}_{t}<\theta /(\theta-1)$. Hence, no matter what the value of $f_{t}^{a}$ is, the reappointment parameter $f_{t}$ will always be smaller than the markup, thus the central bank is less conservative than necessary to ensure commitment and the incentive to increase output ex-post is not offset.

To complete the prove note that if firms expected that the optimal level of the money supply growth is $\hat{x}<\bar{x}$, they will set prices $p_{t}=\left[\frac{\theta}{(\theta-1) \beta}\right]^{\frac{1}{(1-\alpha)}}(\hat{x})^{\frac{2-\alpha}{1-\alpha}}$. As a result the central bank would set the money supply growth such that

$$
x_{t}=z_{t}\left[\frac{\theta}{(\theta-1) \beta}\right]^{\frac{1}{(1-\alpha)}}(\hat{x})^{\frac{2-\alpha}{1-\alpha}} .
$$

As $f_{t}<\theta /(\theta-1)$, one gets that $z_{t}=f_{t}^{\alpha-1}>(\theta /(\theta-1))^{\alpha-1}$. It follows that

$$
x_{t}=z_{t}\left[\frac{\theta}{(\theta-1) \beta}\right]^{\frac{1}{(1-\alpha)}}(\hat{x})^{\frac{2-\alpha}{1-\alpha}}>\left[\frac{\theta}{(\theta-1)}\right]^{\frac{2-\alpha^{2}}{(1-\alpha)}}\left(\frac{1}{\beta}\right)^{\frac{1}{(1-\alpha)}}(\hat{x})^{\frac{2-\alpha}{1-\alpha}}>\hat{x} .
$$

Where the last inequality holds given that $\theta /(\theta-1), 1 / \beta,(1 /(1-\alpha)),(2-\alpha) /(1-\alpha)$ and $\left(2-\alpha^{2}\right) /(1-\alpha)$ are all greater than one.

Hence, the central bank will always increase the money supply growth and by iteration it is optimal for the firm to set prices $(\bar{p})$ expecting $x_{t}=\bar{x}$. The central bank, given $\Pi^{A}$, will confirm that expectation since it is not feasible to increase the money supply growth rate further. Given $\Pi^{A}$ and $x^{A}$, following the household maximization problem, $\omega^{A}$ will be such that $c_{t}=\underline{c}$. As $\bar{x}$ becomes arbitrarily large, $\underline{c}=c_{t}=n_{t} \rightarrow 0$ for all $t$. That way, the economy's welfare under this outcome approaches zero and it will be optimal for the government to minimize its reappointment cost setting $F^{A}=\{1,1\}^{12}$. Hence, the only feasible equilibrium in a Markov economy, due to the fact that the government does not find optimal to constraint the central bank to ensure it does not inflate the economy, is the autarky equilibrium. Given that any Markov equilibrium is also sustainable, the autarky equilibrium is a sustainable equilibrium.

\section{Proof of Proposition 6.}

Given that under autarky $c_{t}=n_{t}$ approaches zero the welfare of the household also approaches zero. As $c_{t}$ approaches zero so does $y_{t}$ and firms' profits. Given that the utility function of the household is always greater or equal to zero (as $0<\alpha<1$ and $c_{t}=n_{t}$ in a competitive equilibrium) and that profits are non-negative under a competitive equilibrium any other sustainable equilibria will deliver greater or equal levels of payoff for both the household and firms. However, the government and central bank objective functions consist of the economy's welfare plus a non-positive adjustment.

\footnotetext{
${ }^{12}$ In fact the same outcome for $\{x, \Pi, \Omega\}$ is observed for any $f_{t}=f_{t}^{a}<\frac{\theta}{\theta-1}$.
} 
Therefore, we must ensure that there is no sustainable equilibria that delivers negative utility for the government and the central bank.

Assume there is a sustainable equilibrium with strategy $\tilde{\sigma}_{2}$ that delivers a negative discounted sum of payoffs to the government from time $t$ onwards. That implies $f_{\tau}<f_{\tau}^{a}$ for some $\tau>t$. However, at time $t$, the government would do better to set a strategy $\hat{\sigma}_{2}$ with $\hat{f}_{\tau}=f_{\tau}^{a}$ for all $\tau>t$ and achieve a discounted sum of payoffs greater than or equal to zero, hence, $\tilde{\sigma}_{2}$ does not solve (GR) at time $t$, invalidating condition (iv) of a sustainable equilibrium.

Finally, assuming $\beta \leqslant x_{t}<\bar{x}$, if the central banks sets monetary policy optimally at period $t$ then $x_{t}=\left(f_{t}\right)^{1 /(\alpha-1)} p_{t}$. Inputting that into the central bank objective function (see problem $\mathrm{CB}$ ) we find that the maximized value of the current period utility is given by $\frac{f_{t}^{\alpha /(\alpha-1)}}{\alpha}-f_{t}^{\alpha /(\alpha-1)}+\frac{\left(f_{t}-1\right) \beta}{p_{t}}$, which is positive as $0<\alpha<1$ and $f_{t} \geqslant 1$. Hence, if the central bank maximizes the period by period utility its total payoff would be positive. In a sustainable equilibria the central bank might not set $x_{t}$ optimally at each period $t$, playing strategically, only to ensure a greater payoff. Therefore, in all other sustainable equilibria but the autarky equilibria the central bank utility must be greater than zero. If the policy constraint, $\beta \leqslant x_{t} \leqslant \bar{x}$, binds above, then $x_{t}=\bar{x}$. In that case we are back at the autarky equilibrium.

\section{Proof of Proposition 7.}

First note that if $\{\widehat{x}, \widehat{\Pi}, \widehat{\Omega}, \widehat{F}\}$ is a sustainable outcome then it must incorporate the optimal responses from firms and the representative household given $\widehat{x}$ at $t=0$. This is equivalent to the condition that firms and the household solve the problems $(\Lambda),(\mathrm{H})$ and the market clearing conditions hold. Therefore, by definition, $\{\widehat{\Pi}, \widehat{\Omega}\}$ is a competitive equilibrium.

Given a history $h_{t-1}$, and an initial delegation parameter $f_{t}^{a}$, the government will confirm the sustainable equilibrium and set $f_{t}$ according to $\widehat{F}$ if and only if its utility from period $t$ onwards is maximized, otherwise, it will deviate at time $t$. The left-hand side of $(a)$ gives the utility if $f_{t}$ is confirmed according to $\widehat{F}$ and the right-hand side the total utility from deviating at time $t$. Hence, if $(a)$ holds, the government does not deviate at time $t$ for all $t=0,1, \ldots$.

The same argument applies to the central bank. If $(b)$ holds, the central bank does not deviate at time $t$ for all $t=0,1, \ldots$. Finally, given that neither the government nor the central bank have an incentive to deviate at time $t,\{\widehat{x}, \widehat{F}\}$ hold, and firms and household optimal allocation rules induce $\widehat{\Pi}$ and $\widehat{\Omega}$ at time $t$. Note that the revert-toautarky plan is a sustainable equilibrium since if at history $h_{t-1}$ there is no deviation, the outcome at time $t$ confirms $\{\widehat{x}, \widehat{\Pi}, \widehat{\Omega}, \widehat{F}\}$ and if there was a deviation in the history $h_{t-1}$, all players play the autarky policies and allocation rules and as proposition 5 shows, that is a sustainable equilibrium. 
WORKING PAPERS*

Editor: Nils Gottfries

2007:17 Annika Alexius and Bertil Holmlund, Monetary Policy and Swedish Unemployment Fluctuations. 27pp.

2007:18 Meredith Beechey and Pär Österholm, The Rise and Fall of U.S. Inflation Persistence. 23pp.

2007:19 Henry Ohlsson and Donald Storrie, Long term effects of public policy for displaced workers in Sweden - shipyard workers in the West and miners in the North. 26pp.

2007:20 Niklas Bengtsson, How responsive is body weight to transitory income changes? Evidence from rural Tanzania. 38pp.

2007:21 Karin Edmark, Strategic Competition in Swedish Local Spending on Childcare, Schooling and Care for the Elderly. 38pp.

2007:22 Fredrik Johansson, How to Adjust for Nonignorable Nonresponse: Calibration, Heckit or FIML? 25pp.

2007:23 Henry Ohlsson, The legacy of the Swedish gift and inheritance tax, 18842004. 25pp.

2007:24 Ranjula Bali Swain and Fan Yang Wallentin, DOES MICROFINANCE EMPOWER WOMEN? Evidence from Self Help Groups in India. 26pp.

2007:25 Bertil Holmlund and Martin Söderström, Estimating Income Responses to Tax Changes: A Dynamic Panel Data Approach. 34pp.

2007:26 N. Anders Klevmarken, Simulating the future of the Swedish baby-boom generations. 60pp.

2007:27 Olof Åslund and Oskar Nordström Skans, How to Measure Segregation Conditional on the Distribution of Covariates. 17pp.

2007:28 Che-Yuan Liang, Is There an Incumbency Advantage or a Cost of Ruling in Proportional Election Systems? 20pp.

2007:29 Stefan Eriksson and Jonas Lagerström, Detecting discrimination in the hiring process: Evidence from an Internet-based search channel. 31pp.

2007:30 Helge Berger and Pär Österholm, Does Money Growth Granger-Cause Inflation in the Euro Area? Evidence from Out-of-Sample Forecasts Using Bayesian VARs. 32pp.

2007:31 Ranjula Bali Swain and Maria Floro, Effect of Microfinance on Vulnerability, Poverty and Risk in Low Income Households. 35pp.

\footnotetext{
* A list of papers in this series from earlier years will be sent on request by the department.
} 
2008:1 Mikael Carlsson, Johan Lyhagen and Pär Österholm, Testing for Purchasing Power Parity in Cointegrated Panels. 20pp.

2008:2 Che-Yuan Liang, Collective Lobbying in Politics: Theory and Empirical Evidence from Sweden. 37pp.

2008:3 Spencer Dale, Athanasios Orphanides and Pär Österholm, Imperfect Central Bank Communication: Information versus Distraction. 33pp.

2008:4 Matz Dahlberg and Eva Mörk, Is there an election cycle in public employment? Separating time effects from election year effects. 29pp.

2008:5 Ranjula Bali Swain and Adel Varghese, Does Self Help Group Participation Lead to Asset Creation. 25pp.

2008:6 Niklas Bengtsson, Do Protestant Aid Organizations Aid Protestants Only? $28 \mathrm{pp}$.

2008:7 Mikael Elinder, Henrik Jordahl and Panu Poutvaara, Selfish and Prospective Theory and Evidence of Pocketbook Voting. 31pp.

2008:8 Erik Glans, The effect of changes in the replacement rate on partial retirement in Sweden. 30pp.

2008:9 Erik Glans, Retirement patterns during the Swedish pension reform. 44pp.

2008:10 Stefan Eriksson and Jonas Lageström, The Labor Market Consequences of Gender Differences in Job Search. 16pp.

2008:11 Ranjula Bali Swain and Fan Yang Wallentin, Economic or Non-Economic Factors - What Empowers Women?. 34pp.

2008:12 Matz Dahlberg, Heléne Lundqvist and Eva Mörk, Intergovernmental Grants and Bureaucratic Power. 34pp.

2008:13 Matz Dahlberg, Kajsa Johansson and Eva Mörk, On mandatory activation of welfare receivers. 39pp.

2008:14 Magnus Gustavsson, A Longitudinal Analysis of Within-Education-Group Earnings Inequality. 26pp.

2008:15 Henrique S. Basso, Delegation, Time Inconsistency and Sustainable Equilibrium. 24pp.

See also working papers published by the Office of Labour Market Policy Evaluation http://www.ifau.se/ 